\title{
A Linguagem Praticada em InTERAÇões VERBAIS ASSIMETRICAMENTE CONSTITUÍDAS: que Palavras Podem Aí Se Apresentar
}

\author{
Language in asymmetrically construed verbal \\ interactions: which words can therein arise
}

\author{
Rosa Helena Blanco Machado* \\ Carlos Alberto Faraco**
}

INTRODUÇÃO

As conversas entre interlocutores em interações sócio-verbais assimetricamente constituídas, entre parceiros distantes, do ponto de vista social, econômico, educacional e cultural, como as situações de que vamos tratar nesse trabalho, em geral são tomadas como conversas em que um dos interlocutores é considerado como o cidadão que tem algo a dizer, o que sabe, o mais habilitado, o usuário de uma língua(gem) correta, legítima e prestigiada; do outro lado do circuito de comunicação está o falante de uma língua menos habilitada, menos aceita, o usuário menos prestigiado e que tem "menos" a dizer, isto é, o seu saber em geral, o seu conhecimento do mundo e do que o cerca é menos aceito ou não aceito. As idéias que circulam ou que devem circular nessas situações de interações sócio-verbais, geralmente, são aquelas do parceiro mais prestigiado, o mais bem colocado na sociedade, em geral ocupante dos ápices da conhecida pirâmide social.

Em conversas em que esse parceiro menos prestigiado ocupa faixas ainda mais baixas da pirâmide social - é o caso, por exemplo, das pessoas que vivem em situação de risco, como os chamados meninos e meninas de rua - a situação tende a ser ainda mais radical, na qual praticamente nada se concede, em que nada se negocia em termos de sentidos e significações que devam circular - ou talvez nem circulem - nessas interações verbais.

Alguns trabalhos sobre as interações verbais, sobre os diálogos

Professora titular da Universidade do Estado da Bahia. Professor Titular da Universidade Federal do Paraná. 
em particular, e aqui estou me referindo aos trabalhos de Linell \& Luckmann (1991), cuidam de descrever esses diálogos e enumerar suas características, as quais, grosso modo, se resumem à partilha de conhecimentos, à mutualidade e à reciprocidade.

Tais características são: a partilha de conhecimento, aquilo que é objetivamente conhecido e compartilhado por pessoas que se engajam em uma situação de comunicação; a mutualidade (mutuality) de conhecimentos e suposições, referindo-se às suposições de cada indivíduo, de que ele divide o conhecimento com os outros com quem se comunica, e que os outros sabem que cada sujeito comunicador faz suas suposições desse conhecimento comum; e a reciprocidade, que, segundo suas próprias palavras, "[...] é inerente também à menor contribuição do diálogo, isto é, o enunciado; tal unidade elementar é dependente da contribuição do outro e é co-determinante da próxima contribuição do outro (LINELL; LUCKMANN, 1991, p. 3).

Sabe-se que não há totalidade na partilha de conhecimentos nem na oportunidade de participação. Assim, a assimetria é um fenômeno que acaba por atingir os diálogos e o discurso em geral, posto que "(Isto significa que) assimetrias e desigualdades de muitos tipos são compatíveis com o mútuo e a reciprocidade". É o que dizem os autores analisando como o fenômeno da assimetria está presente nas interações dialógicas. A assimetria é "um traço intrínseco do diálogo" (LINELL; LUCKMANN, 1991, p. 7) e, mais que isso, "(toma-se como razoável ponto de partida que) todo diálogo envolve assimetrias (desigualdades, não-equivalências, etc.) em diferentes níveis" (LINELL; LUCKMANN, 1991, p. 8):

\begin{abstract}
Em outras palavras, assimetrias e desigualdades são não somente compatíveis com suposições de mutualidade e reciprocidade, elas são também propriedades essenciais de comunicação e diálogo. De fato, se não houvesse assimetrias, absolutamente, entre as pessoas, isto é, se desigualdades comunicativamente relevantes não existissem, haveria pouca ou nenhuma necessidade para muitos tipos de comunicação (LINELL; LUCKMAM, 1991, p. 3-4) ${ }^{1}$.
\end{abstract}

O funcionamento do diálogo, segundo essa perspectiva, está focado no entendimento de que a língua(gem) é um sistema de normas que se põe em funcionamento no momento do circuito da fala, cabendo a cada

A tradução do texto é de nossa responsabilidade. Segue o original: "In other words, asymmetries and inequalities are not only compatible with assumptions of mutuality and reciprocity, they are themselves essential properties of communication and dialogue. Indeed, if were no asymmetries at all between people, i.e. if communicatively relevant inequalities of knowledge were non-existing, there would be little or no need for most kinds of communication! (LINELL; LUCKMAM, 1991, p. 3-4). 
interlocutor, dotado do conhecimento desse sistema, dirigir suas falas ao seu parceiro de comunicação; ao parceiro cabe entender/compreender a fala, processando-a fisio-neurologicamente e cognitivamente.

Pelos conceitos de língua e linguagem aí evidenciados, cuida-se de observar e registrar, em uma dada situação de comunicação, e atentandose para os sujeitos que ocupam as posições de falante/ouvinte, aquilo que foi produzido, por cada um desses interlocutores, a partir do sistema de sinais e de normas de que se constitui a língua, um conhecimento compartilhado pelos parceiros; cabe ao ouvinte/interlocutor pronunciar-se, em retorno, ou calar-se.

Essa abordagem dos diálogos esclarece muitos aspectos sobre o funcionamento dos diálogos, das conversas que travamos no dia-a-dia, nas várias modalidades sob as quais a língua se concretiza: eventos orais e eventos escritos. Por sua leitura, apreendemos melhor o que ocorre nos momentos em que usamos a linguagem, permitindo dirigir um olhar mais preciso sobre o que devemos ou não devemos fazer em situações específicas de uso de linguagem, tal como, por exemplo, nas situações de sala de aula - em que medida interessa à Escola essas interações, essencialmente assimétricas, e quais são as implicações disso para o ensino/aprendizagem? Como seu entendimento pode ajudar o processo da formação, da educação?

A assimetria pode se dar em vários níveis e pode ser uma assimetria geral ou local, a depender dos limites até onde se estendem seus efeitos. Assimetria sugere a idéia de um desequilíbrio na valoração do objeto - $a$ fala - levando à consideração de que um dos pólos da conversa, um dos seus interlocutores é, naturalmente, o de maior autoridade, o de maior força/ poder, nessa relação que se estabelece aí, fazendo pender para este pólo o prestígio e a aceitação do que aí é significado e da forma como é significado.

Entretanto, tal perspectiva não diz nada sobre a natureza dessa assimetria, que pode fazer, por exemplo, silenciar uma boa parcela de falas, em geral aquelas de menor valor social, isto é, aquelas falas do interlocutor de menor prestígio. Como também pode levar à compreensão apressada de que tal silêncio, ou a evasiva ou a recusa em responder se devem tão somente a uma performance condizente com o potencial cognitivo do nosso interlocutor, ou a um possível déficit de informações relativamente ao que lhe foi perguntado.

Se, de fato, os diálogos funcionam, por sua própria natureza, assentados em posição de assimetria, em razão da impossibilidade de haver partilha total de conhecimentos, de suposições, de idéias, de pontos de vista, enfim, deve-se, por outro lado, considerar a possibilidade de que há uma diferença aí, entre os pontos de vista, entre os tons atribuídos aos diversos temas, à palavra, ao discurso, e essa diferença é trazida à baila e revelada 
justamente nessa assimetria, pela ausência, nesses diálogos, desses pontos de vista, desses conhecimentos. Assim, a noção de assimetria, que nos diz que alguém é detentor de um saber não disponível ao seu parceiro de comunicação, traz consigo também a idéia de que esse parceiro pode apresentar uma "versão" do tema que pode não ter o tom do objeto tal como o concebe o interlocutor de maior prestígio. E essa desigualdade em torno à significação atribuída ao objeto pode ser tomada como um ponto de desequilíbrio. Daí ter-se uma situação de assimetria.

Outras perspectivas de estudo da língua(gem), porém, podem fazer ver aí outros elementos entrando em cena para justificar a presença tão forte dos silêncios ou das recusas em responder questões do tipo tal qual aquelas que foram motivo deste estudo. Essas questões, em geral, são vinculadas a temas relacionados a discursos institucionais ou discursos que envolvem fortes componentes da ordem institucional sob os quais as sociedades modernas como a nossa devem funcionar. Os dados que analisamos permitem e necessitam de uma análise não tão redutora na explicação da ocorrência desses silêncios e dessas evasivas, comportamentos muito observados em nossa pesquisa. O que propomos então é um olhar diferenciado para esses comportamentos lingüísticos tão comuns em conversas do tipo que aqui apresentamos.

\section{Os Diálogos Assimétricos e a Perspectiva da Heteroglossia do DISCURSO}

Quando se analisam conversas (entrevistas realizadas com a finalidade de obter dados para estudos ou conversas espontâneas) do tipo referido aqui - assimetricamente constituídas - são muitas vezes encontradas situações que trazem à baila essas questões. Ou, por outra, as conversas assimetricamente constituídas de interlocutores distanciados do ponto de vista sociocultural, mostram, com mais clareza, a emergência dessas desigualdades. Ou seja, nessas conversas evidenciam-se mais facilmente situações em que as significações em torno aos temas trabalhados parecem não ser as mesmas para os dois parceiros: a apreensão do objeto do discurso pode ser diferentemente valorada ou, talvez, o tom, o acento, conferido à significação do tema se mostre diferente para os dois interlocutores. Dessa desigualdade no tratamento ao tema parece decorrer então a idéia da assimetria de discurso e, em conseqüência, a valoração de uma das falas, aquela do interlocutor de maior prestígio.

A idéia da palavra atravessada pela acentuação, pelo tom que lhe dá o falante, a idéia de uma palavra que deve ser pensada não no mostruário 
do sistema de normas, mas mergulhada no circuito da comunicação, na interação viva entre as pessoas, circunstanciada em um espaço-tempo, a plurivocalidade, estão nas reflexões de Bakhtin, em todas as suas obras disponíveis, incluindo-se aí aquelas cuja autoria não lhe é atribuída com certeza absoluta.

A reflexão que aqui fazemos, a partir da perspectiva bakhtiniana de língua e da linguagem, da consideração do traço dialógico enquanto constitutivo do discurso, vivido em situação de interação socioverbal, da consideração da heteroglossia, tem o objetivo de verificar mais de perto o funcionamento dessas relações assimetricamente constituídas e por em questionamento as suposições que sustentam a compreensão mais aceita dessa assimetria, fincada no entendimento de que um dos interlocutores, o mais bem situado, do ponto de vista socioeconômico e cultural, aquele para quem pende a balança, é o interlocutor de maior prestígio, e sua fala é tida como aquela que tem conteúdo e forma "verdadeiros". As falas desses interlocutores são discursos cujas significações se tomam como adequadas e/ou mesmo corretas, em contraposição ao que é significado - ou ao que é silenciado - pelo outro interlocutor. Essas abordagens sobre a língua(gem), o discurso e a significação estão fundamentadas na idéia de língua como um sistema rígido de sinais, um sistema monológico que rege e controla os significados. Essa abordagem não considera a palavra, o discurso realizado efetivamente em uma situação socioverbal; não avalia o peso das interações verbais para a vida da palavra, não mensura a caminhada da palavra nos vários momentos em que ela foi significada por ambos os interlocutores. Enfim, não vê a natureza dialógica da palavra.

Em seu texto de 1930, o discurso no romance, tecendo considerações sobre a natureza concreta da língua, em oposição à abstração pura do sistema lingüístico das correntes lingüísticas em vigência, para examinar a heteroglossia do gênero romanesco, Bakhtin $(1988$, p. 96) diz:

\begin{abstract}
A língua, enquanto meio vivo e concreto onde vive a consciência do artista da palavra, nunca é única. Ela é única somente como sistema gramatical abstrato de formas normativas, abstraída das percepções ideológicas concretas que a preenchem e da contínua evolução histórica da linguagem viva. A vida social viva e a evolução histórica criam, nos limites de uma língua nacional abstratamente única, uma pluralidade de mundos concretos, de perspectivas literárias, ideológicas e sociais, fechadas; os elementos abstratos da língua, idênticos entre si, carregam-se de diferentes conteúdos semânticos e axiológicos, ressoando de diversas maneiras no interior destas diferentes perspectivas.
\end{abstract}

A palavra, vista dessa forma, permite a compreensão de "uma 
pluralidade de mundos concretos", permite a aceitação de diferentes visões de mundo a serem apreendidas a partir da língua enquanto sistema mas carregado de diferentes conteúdos semânticos absorvidos na corrente histórica da vida da língua(gem), em sua evolução. As significações não devem ser aprisionadas em um sistema lingüístico fechado em si mesmo e abstraído das percepções ideológicas concretas que nos cercam enquanto falantes de uma língua(gem), afetados por condições sociohistóricas e ideológicas.

Esse ponto de vista pode ajudar a entender melhor o que ocorre em situações de interação verbal como a que transcrevemos abaixo, fragmento de uma entrevista do tipo já caracterizado como um diálogo assimetricamente constituído. $O$ entendimento das significações que são ali emergentes e trabalhadas, no que diz respeito a noções ligadas a discursos institucionais como aqueles discursos que dizem respeito à família, à escola, à polícia, à sociedade, à religião etc., problematizam a compreensão de uma semântica que não absorve a palavra marcada por sua história ideológica e social, isto é, uma semântica fechada e estática que não considera movimentos do discurso no fluxo da história desenrolada por entre os vários grupos sociais em que ela circula. Ou, por outro lado, problematiza essa mesma situação, marcando-a como uma não resposta por parte do interlocutor de menor prestígio, o qual, diante dessas situações, cala-se, evade ou recusa-se a responder.

Em situações de fala como²:

ENT. $^{3}$ _ Não sei quem é não, não sei. Você, portanto, tem seu pai... não mora com você mas tem o seu pai, tem a sua mãe, tem seu irmão... G. você acha importante ter família, não é?

- Acho.

2 Trechos de entrevistas realizadas pela pesquisadora com crianças e adolescentes de rua, atendidos pelo Projeto Cidade Mãe, nas dependências da Casa Dom Timóteo e Casa de Oxum, em Salvador-Bahia, 1996.

Nas transcrições dessas e de outras gravações de entrevistas que servem como corpus deste trabalho, utilizamos alguns procedimentos de escrita de modo a melhor entendermos o movimento do diálogo que ali se desenrola. São eles:

- A primeira fala é sempre, nos trechos transcritos, do/a Entrevistador/a. Dáse seqüência então ao diálogo com as falas alternadas dos parceiros da conversa;

- Utilizamos os parênteses com reticências em seu interior para marcarmos um trecho que foi deliberadamente omitido da transcrição;

- Utilizamos colchetes também preenchidos com reticências para marcarmos passagens inaudíveis ao gravador, ou colchetes preenchidos com os possíveis segmentos a partir da audição;

- Utilizamos chaves quando queremos/entendemos ser necessário informar sobre as circunstâncias da entrevista; ou quando queremos explicar fatos de natureza lingüística. 
Por que minha filha? Por que que você acha que ter família é importante?

[Silêncio]

_ Diga do jeitinho que você achar que é... Ajuda as pessoas, ter família?

_ Ajuda.

(...)

Então, prá você, como é que a família pode ajudar as pessoas? Você tem... que é que você acha disso?

- [Silêncio]

_ Se família é bom ou não é bom? Se pode ajudar uma mocinha, um menino? Como é? Que é que você acha disso?

- [Silêncio]

Eu sei que você sabe, eu sei que você tem seu pensamento [-]É do jeito que você acha que tem que dizer.

_ [Não sei dizer]

Não sabe? Mas você acha que família ajuda?

_ Ajuda sim, numas coisa.

Ajuda numas coisa. Em quê?

- [Silêncio]

- Repare bem: uma menina que tem uma família, uma menina que não tem... família. Que é que é mais interessante?

_ Ter a família e ficar [sempre junto da família]

- Sim. Por que?

_ Eu acho mais protegido.

- Mais protegida né, tia? Mais protegida e que mais?

- Sei lá.

A mãe protege mais, não é isso? Você não sente falta de sua mãe, assim na rua?

_ Sinto [sempre] eu fico pensando nela.

o entendimento geral do que aí se passa, nesse fragmento de diálogo entre uma pesquisadora mais velha, de classe social mais prestigiada, professora e essa adolescente, gira sempre em torno de que ocorre aí uma dificuldade evidente da menina em falar sobre família; algumas hipóteses podem ser aventadas, inclusive a que explica que ocorre pouca familiaridade com o gênero textual solicitado à entrevistada, que seria eliciado pelo tipo de pergunta que se faz, visando deflagrar um texto expositivo-argumentativo. Esse texto argumentativo que se esperava, de fato não acontece, pelo menos não como o entendemos e como o concretizamos. Mas há, sem dúvida, incursões da menina em torno ao que lhe foi perguntado, ainda que sua fala esteja cercada de hesitação, de evasiva e de silêncio. A princípio, a menina concorda quanto ao papel da família, embora não dê qualquer justificativa. Segue-se mais um período de silêncio, até que, cercada pelas perguntas da pesquisadora, tem-se a passagem: 
ENT. _ Não sabe? Mas você acha que família ajuda?

_ Ajūa sim, numas coisa.

- Ajuda numas coisa. Em quê?

_ [Silêncio]

A fala da menina está permeada pelo silêncio: ela se recusa a falar do tema proposto e o silêncio emerge com força nessa entrevista como em tantas outras que obtivemos ao longo da pesquisa que realizávamos, todas essas entrevistas com as mesmas características. A pergunta que se faz com insistência aí é: por que ocorre esse silêncio, essa hesitação? O que ele significa?

A fala que aí esperávamos e que não acontece é a fala sobre o tema da família, sempre tendo em mente a família tal como a concebe a interlocutora entrevistadora. O que se propunha à menina era sua (dela) exposição sobre o tema da instituição familiar, considerando sua função, importância para a sociedade e composição. Acreditava-se que sendo esse um tema das sociedades modernas e que família, nos termos em que é descrita oficialmente, é a forma básica de organização societária, a sua significação fosse, falando em termos gerais, plenamente praticada na sociedade, de modo unívoco e acessível para todos. Mas esse discurso não aparece. Em seu lugar surge o silêncio, a evasiva.

Algumas hipóteses para esse comportamento lingüístico podem ser aventadas. Por exemplo, a de que a interlocutora de menor prestígio social, sabedora de que a sua não é a fala aceita e considerada, e levando em conta ademais que é uma pessoa que se encontra, naquele momento, dentro de uma instituição social que lhe assegura alguma assistência ${ }^{4}$, resolve que não responder pode ser uma alternativa, já que o seu entendimento sobre a questão, se diferenciado, poderá levar a um julgamento que lhe é desfavorável.

Entendemos que essas performances do sujeito falante podem efetivamente funcionar; isto é, que devemos, em momentos em que nos é possível deliberarmos sobre a linguagem e o que podemos/devemos fazer com ela, adotarmos, de algum modo, conscientemente, algum caminho na escolha, na seleção, na opção de falar ou de silenciar. É uma ação do sujeito falante que tem algum poder de decisão.

Entretanto, essa perspectiva, quando considerada tão somente por esse viés, também pode enfatizar a compreensão de que a língua é de fato

\footnotetext{
Essas entrevistas foram realizadas dentro da Sede do Projeto Cidade Mãe, Casa de Oxum, destinada a acolher meninas de rua. Naquela época, às meninas que viviam nas ruas era oferecida uma merenda, todas as tardes, para que elas pudessem pouco a pouco se interessar pelo Projeto e, espontaneamente, aderir e incorporar-se ao grupo.
} 
um sistema de sinais e normas, abstrato e fechado em si mesmo, um sistema monológico que o sujeito utiliza, ao fazer a sua opção. Já para a Análise do Discurso francesa, o recurso não é o mesmo. Segundo a AD francesa, o procedimento no caso é apreender as regularidades dessas discursividades, fazendo a devida correlação entre a posição-sujeito, a formação ideológica e a correspondente Formação Discursiva que permite dizer tal coisa e não outra.

A fala de família que esperamos é uma fala moldada em outras esferas, não é uma fala do contexto contemporâneo, é uma fala impositiva. É uma fala que vem de outro lugar. Nos poucos momentos em que a menina resolve falar, o que ela diz sobre a família não corresponde ao discurso autorizado sobre essa instituição basilar de organização da sociedade moderna: em suas palavras "uma família pode ajudar numas coisas e noutras, não". No discurso institucionalizado sobre a família a família deve sempre ajudar, a família sempre ajuda. Esse é o discurso oficial, autorizado. É discurso divulgado pela própria família, pela Igreja, pela Escola, pela Sociedade organizada e controlada.

Numa perspectiva de língua(gem) entendida como uma atividade dialogizada, em que a palavra é naturalmente dialógica, em que a nossa palavra é sempre também palavra do outro, a compreensão do que acontece na situação de fala deve-se dar também a partir da análise de como ocorre a transmissão da palavra alheia e sua incorporação/assimilação à nossa. Isso significa distanciar-nos de uma compreensão da língua que se resolve por si mesma enquanto um sistema de sinais fechado em seus limites; leva a entender que as significações devem ser estudadas no movimento da palavra em meio à vida social em que a linguagem é utilizada. Para Bakhtin (1988, p. 85):

\begin{abstract}
O discurso do pensamento estilístico tradicional conhece apenas a si mesmo (isto é, a seu contexto), seu objeto, sua expressão direta, somente como um discurso neutro da língua, como discurso de ninguém, como simples possibilidade. 0 discurso direto, tal como é entendido pela estilística tradicional, na sua orientação para o objeto encontra apenas a resistência do próprio objeto (a inexaustão da palavra, o seu caráter inefável), porém ela não encontra, no seu caminho para o objeto, a resistência substancial e multiforme do discurso de outrem, ninguém a incomoda nem a contesta.
\end{abstract}

A estilística tradicional, sob a qual estamos acostumados a compreender esses fatos de linguagem, nos faz ver, na resposta do outro, uma palavra que não contempla nenhuma "resistência do discurso de outrem", uma palavra não matizada, que não recebe tons nem acentos, por isso mesmo uma resposta que não pode incomodar nem servir de contestação: 
a palavra deve ter apenas aquela compreensão, aquele sentido. Fugir a esse sentido é não conhecer a palavra, é desconhecer-lhe o significado, único. $O$ estudo da língua(gem) não tem sido no sentido de incorporar esses matizes e tons que as pessoas emprestam ao discurso, submetido ao ritmo das falas das quais as pessoas participam. Espera-se então que o entendimento do objeto seja igualmente monológico, não tocado pela acentuação que lhe emprestam as várias situações nas quais aquela palavra já foi significada.

Bem diferente é a proposta de Bakhtin, que possibilita a compreensão do objeto enquanto um sinal "amarrado e penetrado por idéias gerais, por pontos de vista, por apreciações de outros", isto é, uma compreensão que desfaz a idéia de monologia do sistema lingüístico, a idéia de um sentido universal e único que toca aquela palavra, aquele objeto:

\begin{abstract}
Mas todo discurso concreto (enunciação) encontra aquele objeto para o qual está voltado sempre, por assim dizer, já desacreditado, contestado avaliado, envolvido por sua névoa escura ou, pelo contrário, iluminado pelos discursos de outrem que já falaram sobre ele. O objeto está amarrado e penetrado por idéias gerais, por pontos de vista, por apreciações de outros e por entonações. Orientado para o seu objeto, o discurso penetra neste meio ideologicamente perturbado e tenso de discursos de outrem, de julgamentos e de e entonações (BAKHTIN, 1988, p. 85-86, grifo nosso).
\end{abstract}

No estudo da heteroglossia romanesca, especificamente sobre seu funcionamento e sobre as formas de introdução da palavra de outrem nesse discurso, uma questão se torna importante para Bakhtin (1988): o tema do homem que fala na esfera extraliterária da vida e da ideologia. Como se dá essa transmissão? Que procedimentos levam à transmissão (e assimilação) das palavras de outrem em nosso discurso?

A heteroglossia no romance se realiza por formas diferenciadas. Analisando textos de prosa literária, o autor discute (BAKHTIN, 1988, p. 107-150) sobre como funcionam essa heteroglossia, a pluralidade de vozes, a pluralidade de estilos naquele gênero de texto literário. Fala da pluralidade estilística porque há uma pluralidade de vozes e considera que o romance é o texto que "permite" o aparecimento de outros "entendimentos" sobre o tema tratado, isto é, de outras vozes: discute a questão do dialogismo, para ele inerente, constitutivo da língua(gem) enquanto organismo vivo e atuante, que se presentifica nas situações de interação socioverbal. Não ver a língua(gem) por esse viés significa, para Bakhtin, ver o seu objeto de estudo somente parcialmente iluminado: o que se disser desse objeto não explica o seu funcionamento, a vida da palavra. 
No estudo da fala de outrem e de sua assimilação numa esfera extraliterária, isto é, na esfera da vida cotidiana dos homens e das mulheres em sociedade, Bakhtin busca verificar não os mecanismos de representação dessa língua(gem) mas os meios de sua transmissão. Nesse percurso do seu projeto de reflexão em torno à heteroglossia e ao dialogismo, o estudo da palavra do outro toma aqui um caminho em direção à questão da formação ideológica dos homens: compreender a introdução da palavra do outro vai iluminar a compreensão sobre a evolução ideológica do homem: "um processo de escolhas e de assimilação das palavras de outrem" (BAKHTIN, 1988, p. 142).

Essa palavra de outrem assume aqui, neste processo de formação ideológica do homem, um matiz diferenciado, relacionado às "bases da nossa atitude ideológica em relação ao mundo e (de) nosso comportamento" (BAKHTIN, 1988, p. 142). Duas categorias são propostas então de conceituação da palavra de outrem no processo de transmissão do discurso: a palavra de autoridade e a palavra internamente persuasiva.

A PALAVRA DE AUTORIDADE E A PALAVRA INTERNAMENTE PERSUASIVA: COMO ELAS CONCORREM PARA A FORMAÇÃO DA CONSCIÊNCIA IDEOLÓGICA Do INDIvíduo

A formação ideológica do indivíduo se faz no espaço de entendimento e desentendimento entre essas duas categorias da palavra de outrem; só muito raramente se pode ter uma junção e a ocorrência simultânea das duas categorias da palavra, a de autoridade e a internamente persuasiva, em uma só, embora isso possa ocorrer.

O embate entre a palavra de autoridade e aquela internamente persuasiva marca a caminhada e a expressão ideológica do indivíduo. É então que ocorre o processo de "escolha e de assimilação das palavras de outrem" (BAKHTIN, 1988, p. 142).

Essas duas categorias de palavra do outro, e as formas de sua transmissão, parecem acontecer de um modo alheio ao indivíduo, isto é, ele não tem necessariamente de ter consciência sobre o que ocorre com o seu processo de formação ideológica. São duas categorias diferenciadas, cada uma das quais encontrada em circunstâncias específicas e absorvida diferentemente pelas pessoas, nos vários momentos de uso da linguagem, na sociedade. A transmissão, com mais ênfase de uma ou de outra palavra, fará a diferença entre as pessoas, do ponto de vista de sua formação ideológica, levando à caracterização de uns e outros conforme o peso que cada uma dessas palavras tem/teve para essa formação. 
A palavra de autoridade é, como o seu nome já indica, uma palavra que está associada ao poder. É a palavra "que já existe". No dizer de Bakhtin (1988, p. 143), ela é já "encontrada de antemão. [...] Ela ressoa numa alta esfera e não na esfera do contacto familiar". Nela não cabem modificações, devemos aceitá-la como um bloco fechado, "ela entra em nossa consciência verbal como uma massa compacta e indivisível, é preciso aceitá-la por inteiro ou recusá-la na íntegra" (BAKHTIN, 1988, p. 144).

A palavra de autoridade é, enfim, nas palavras de seu criador, "a palavra do pai": aquela que não escolhemos, ela nos preexiste, ela nos é imposta, e nós podemos ter com ela uma relação "fervorosa ou hostil". É a palavra da religião, da ciência, a palavra da autoridade, que a ela está relacionada. E ela pode ser tocada pela profanação, posto que é como um princípio, como um tabu. Por fim, a palavra de autoridade não é assimilada senão quando se tem o seu reconhecimento.

A palavra de autoridade não se mistura facilmente com as nossas palavras; ela permanece em meio às outras como uma unidade estanque, de difícil penetração e/ou modificação. Ela pode significar a autoridade por si mesma, o oficialismo, o tradicionalismo, o universalismo (BAKHTIN, 1988, p. 143). É uma palavra distante da nossa contemporaneidade, diferentemente da palavra internamente persuasiva, essa que dirigimos para o nosso tempo, e para o nosso descendente como um contemporâneo.

A palavra internamente persuasiva "carece de autoridade, não se submete a qualquer autoridade, com freqüência é desconhecida socialmente (pela opinião pública, a ciência oficial, a crítica) e até mesmo privada de legalidade" (BAKHTIN, 1988, p. 143).

A palavra persuasiva internamente parece caminhar por vias bem diferentes daquelas palmilhadas pela palavra de autoridade. Esta última, só a assimilamos, de fato, se nós a reconhecermos, se lhe conferirmos esse poder de autoridade. Ou seja, ela existe antes, de antemão, mas só nos atingirá se lhe dermos esse reconhecimento. Ela pode juntar-se à nossa palavra internamente persuasiva, ainda que seja através de uma relação hostil. E ela virá sem se misturar à massa da palavra internamente persuasiva.

No fragmento da entrevista transcrito acima, na voz e no silêncio da menina, parecem estar atuando efeitos dessa palavra de autoridade. Em outras palavras, parece haver aí uma recusa em falar de família, que pode ser entendida como uma recusa por não se ter rendido ainda à palavra de autoridade.

o discurso de família, atravessado pela palavra de autoridade, é o que a instituição diz que família é (ou deve ser) e está ligado ao poder. Parece, porém, não ter ainda reconhecimento por parte do interlocutor 
entrevistado. A interlocutora, para assimilá-lo deve reconhecê-lo. Isso parece não ter acontecido; nesse momento, a palavra de autoridade ainda está distante. Mas pode vir a assimilá-la. A situação de silêncio, de fuga à resposta à questão proposta, podem ser indícios de que o reconhecimento de autoridade a que está ligada essa palavra pode vir a acontecer. Esse silêncio pode mostrar uma relação não hostil, em relação à palavra de autoridade: a resposta da menina não é uma resposta de recusa à palavra de autoridade sobre família que subjaz àquela conversa e de que a menina, de algum modo se apercebe. $O$ silêncio parece indiciar um não reconhecimento ainda da palavra de autoridade; por outro lado, pode sinalizar uma reorientação na formação ideológica desse indivíduo, se considerarmos que a fala da interlocutora não aponta totalmente para a negação dessa palavra de autoridade. Também não existe aí a profanação da palavra de autoridade. 0 que também pode acontecer, como veremos mais adiante.

Em outra entrevista também realizada na mesma ocasião, realizada nas mesmas condições desta que acabamos de expor, há uma passagem intrigante, diríamos, na resposta do menino entrevistado, quando solicitado a falar também de família.

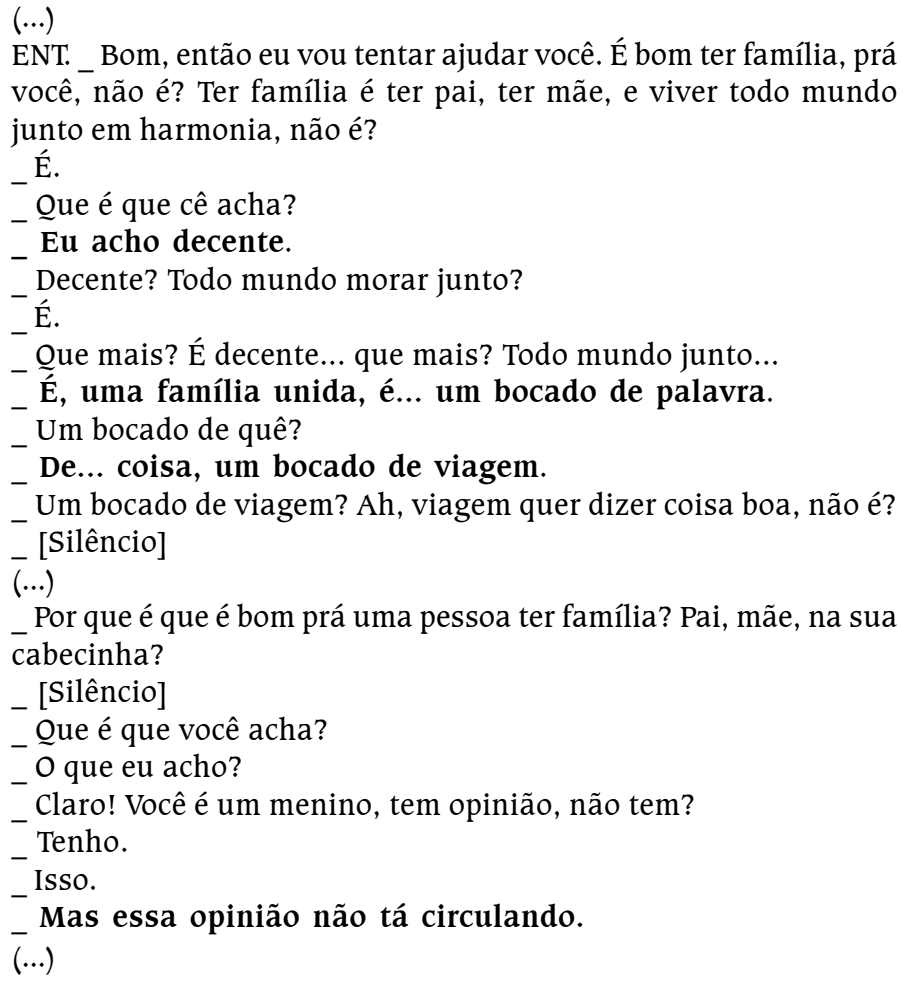


Aqui, é de total perplexidade a impressão que nos causa essa fala sobre o tema de família: para o garoto, família é "um bocado de palavra, um bocado de viagem". Mais do que qualquer outra tentativa de explicação dessas palavras do garoto em torno ao tema de família, aquela que aponta para a natureza desse discurso como uma resposta a um discurso distante, nascido em outro lugar, não contemporâneo, enfim, a palavra de autoridade, constitutiva do discurso de sua interlocutora, é a que parece tocar com mais propriedade, sua essência e sua natureza. Para o garoto, essa é uma palavra de autoridade que ele ainda não assimilou mas de que já tem conhecimento. São palavras distanciadas do seu contexto. "São palavras encontradas de antemão". O discurso do menino é de assentimento ao que a interlocutora havia descrito como família, de que ela pede um pronunciamento. Ele o dá qualificando o que a sua interlocutora diz sobre família como "algo decente, um bocado de palavra, de viagem".

Em seguida, motivado pela observação da interlocutora de que ele é um "menino, tem opinião própria", ele diz que "essa opinião não tá circulando". O falante tem consciência de que seu discurso, sua palavra diferencia-se daquela sobre família que a interlocutora tenta impor. Sua opinião faz parte da palavra internamente persuasiva, aquela que "carece de autoridade, é desconhecida socialmente, e até mesmo privada de legalidade" (BAKHTIN, 1988, p. 143). Talvez aí resida essa reticência, essa resistência do garoto em responder. Ele ainda não reconhece a autoridade dessa palavra.

O fragmento abaixo é transcrito de uma conversa/entrevista gravada por uma professora universitária com um garoto de 15 anos, que está sendo, já há algum tempo, assistido por um órgão religioso de serviço social, em Salvador, Bahia ${ }^{5}$. O garoto, conforme se depreende da conversa, chegou a freqüentar as ruas de Salvador para obter algum dinheiro com o qual ajudava sua mãe em casa.

A passagem vai evidenciar, na conversa com a interlocutora uma professora pesquisadora que o entrevista com finalidade de estudos na área de Ciências Sociais -, que há uma mudança de compreensão e de aceitação da noção de Escola, essa que é uma das mais fortes instituições de nossa sociedade. Retoma-se, pela linguagem, um entendimento anterior do que o menino achava da instituição Escolar, sobre sua função e sua importância, e o que mudou em relação a isso.

\footnotetext{
A entrevista me foi gentilmente cedida, ainda na sua forma gravada, pela professora Iara Dulce B. de Ataíde, professora da UNEB e da UCSAL. A transcrição da entrevista foi feita por mim mesma. O órgão de assistência de que se fala é o ICAJ - Instituto Cristão de Atendimento aos Jovens. Salvador-Bahia.
} 
ENT. _ Você freqüentou a escola, não freqüentou?

_ Eu só freqüentei só foi a primeira série. Ai eu comecei a um dia à ir, outro não, dia sim dia não, e indo para a rua, que...

_ Por que que você não gostava da escola?

- Porque eu queria ir para sinaleira, queria mais era ajudar minha mãe, ai não...

- Não achava a escola importante não?

- Não, pra mim a escola era só... coisa que tinha que ir, só pra escrever mas não tinha importância, pensava que importante pra mim era sinaleira, que eu ia ajudar minha mãe, na sinaleira eu ia arranjar um trabalho melhor, ai eu ia ajudar minha mãe melhor, na escola não, eu ia só ficar escrevendo e sem ganhar nada... ajudar minha mãe... depois eu...

_ Hoje você mudou de idéia a respeito da escola? o que é que você pensa da escola?

- Mudei. Hoje eu penso que a escola... que é muito melhor, a pessoa aprende a ler a escrever e quem sabe, amanhã ou depois arranja um trabalho melhor que possa mudar de vida. Eu só mudei... pensando que a escola era uma coisa chata (...) quando eu vim morar na instituição, que Edu me explicou que eu tinha que ir para o colégio porque a escola é bom, ajuda as pessoas a aprender ler, escrever, aí foi que eu (...) a gostar da escola, eu fui alfabetizado pela moça.

Há uma palavra aqui em torno ao tema, a Escola, que diz que Escola não vale para nada, você vai lá somente para escrever, mas se você quiser obter algum dinheiro para sua sobrevivência de todo dia você terá de ir para as ruas, para a sinaleira. Lá está o mais importante, que é o dinheiro com o qual se enfrenta as dificuldades do cotidiano. Mais ao final da passagem já se pode depreender um outro entendimento de instituição escolar, que não chega a esse garoto, senão quando ele entra para a instituição de assistência e acolhimento: a Escola como algo bom e que ensina coisas importantes: ler, escrever.

É evidente que a Escola fazia parte das significações no entorno desse menino, antes de ele entrar no programa de socialização, mas para ele a significação de Escola não implicava em sua importância, sob aspecto algum; era, mais do que isso, uma significação nula em termos de alguma coisa que o pudesse ajudar a enfrentar as vicissitudes de um dia-a-dia marcado pela dificuldade e pela precariedade; a Escola não existia para ele como um meio através do qual o ser humano pode superar a si e as adversidades que encontra em seu caminho, pela transmissão do conhecimento e pela formação geral que a Escola diz proporcionar. A Escola era tão somente um espaço para escrever mas que não lhe traria a solução para sua vida. 
A idéia de Escola como importante e fundamental instituição para a vida das pessoas, sentido contido, implicitamente, na questão da pesquisadora - Não achava a Escola importante não? - não se realizava para ele. A Escola, vista por esses olhos, é uma palavra de autoridade que o menino não reconhecia e que não está assimilada até que suas interações socioverbais assumem outro contorno - o que acontece a partir do momento em que ele passa a freqüentar a instituição de acolhimento. As novas situações vividas por esse menino, com novos agentes sociais, em diferentes contactos sócio-historicamente marcados, em relação ao que antes ele vivenciava, vão fazer aquela palavra, antes mergulhada em uma significação resultante de suas diversas experiências e contactos, ser tomada de outros sentidos. Aqui a palavra escola já apresenta, na fala do menino, uma reorientação em direção à palavra de autoridade. E aí ocorre o processo de assimilação da palavra de outrem: no caso, da palavra de autoridade que lhe chega através da própria instituição que o acolhe, após o contacto e o percurso feito junto a essa instituição. A aceitação da palavra de autoridade, o reconhecimento de que fala Bakhtin, não se faz tão abruptamente como se pode pensar; o sentido de Escola como uma instituição necessária e importante para a formação do indivíduo não é transparente nem único. A aceitação da palavra de autoridade e seu reconhecimento devem requerer procedimentos e processos de convencimento de alguma natureza, até que este sentido seja internalizado pelo indivíduo e vá assim concorrer para a sua formação ideológica.

Para Bakhtin, no processo de constituição da consciência individual, ocorre um embate entre essas duas palavras: a palavra de autoridade e a palavra internamente persuasiva. A palavra internamente persuasiva é a que concorre mais efetivamente para o processo de constituição de nossa formação ideológica. No processo de transformação ideológica da consciência individual, "quando começa o trabalho do pensamento independente experimental e seletivo, antes de tudo ocorre uma separação da palavra persuasiva da palavra autoritária imposta [...]" (BAKHTIN, 1988, p. 145).

No processo de formação da consciência ideológica dos indivíduos, esses embates devem acontecer de modos diferenciados, a depender das situações de interação socioverbal que cada um vive e do modo como essas interações se dão, sob que condições de produção e que interlocutores estão em cena. Na entrevista, o garoto chega a esclarecer de onde surge esse novo discurso, no caso, atribuído ao agente social, de nome Edu, que atua naquele serviço de assistência. Os caminhos percorridos por esse menino são bastante diferentes dos caminhos tomados pelo garoto da entrevista anterior. Para aquele garoto, o que é dito institucionalmente sobre família não lhe toca, nada lhe diz; assim como para este garoto aqui entrevistado, a Escola também 
nada tinha a dizer. Em ambos os casos nos deparamos com o que Bakhtin chama de palavra de autoridade, aquela que para ser assimilada deve ser reconhecida em sua autoridade.

\section{A Profanação da Palavra de Autoridade}

Por outro lado, em entrevistas caracterizadas também como discursos assimétricos, realizadas por estudantes universitários com meninos de rua, mas em condições distintas daquelas vistas anteriormente, pois que estes meninos de rua vivem completamente nas ruas e do que as ruas lhes oferecem, encontramos discursos sobre esses mesmos temas, os quais, declarada e até acintosamente, se impõem a entendimentos oficiais a respeito dessas noções institucionais e sociais vigentes em nossas sociedades, recusando e afrontando os sentidos oficialmente circulantes a seu respeito:

ENT._Que é que você acha do Brasil? Que é que você acha do país que você vive, assim?

Eu acho que XX \{referência a um político\} é muito corno.

- É muito o quê?

- Ele é corno que não dá uma casa prá gente morar. Só dá rua, manda os homes matar a gente, não dá [-]

(...)

_ Por que você acha que a polícia age assim? Por que você acha que a polícia é assim?

_ Porque você cair, cair sem sunga, você dorme nú...

_ Por que eles fazem isso? Por que você acha que eles fazem isso?

- Porque é ordem do governo, porque o governo é muito ladrão...

XX \{referência a um político\}, ele tem de morrer.

_ E o Juizado de Menores é o quê? O que é que você acha dele?

_ Juizado... eu acho que ele é muito descarado, que gosta de prender os de menor.

_ Você acredita em Deus?

_ Acredito em Deus e ni Jesus.

_ Você já freqüentou alguma igreja, alguma vez já foi?

_ Já... a minha igreja...

_ Alguma igreja lhe ajudou em alguma coisa?

_A minha igreja é só fumar maconha, partir relógio e descer avoado aí...

_Só...

[Risos]

_E Cristo, quem é Cristo para você?

- Cristo é aquele que tá lá no céu.

_ Quando você crescer você quer ser o quê?

_Eu quero ser um assaltante de bo... banco, ser um bicho solto. 


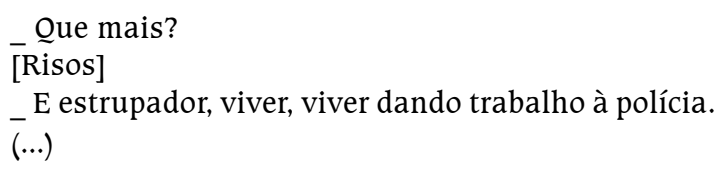

Nessa entrevista não há registro de silêncio. $\mathrm{O}$ adolescente fala tudo o que acha que deve falar e não foge às perguntas. É um garoto de rua, entrevistado na rua mesmo. Não está integrado a qualquer programa de ressocialização, de assistência. É um garoto de rua que vive tão somente daquilo que a rua dá.

Indagado sobre polícia, governo, religião, entre outras coisas, o entrevistado é generoso em suas respostas, mas sem dúvida, tudo o que diz a respeito dos temas solicitados, não atende em nada ao discurso convencional a respeito desses temas: o governo é ladrão; o político $X$ deve morrer; a igreja dele (sua religião) é fumar maconha, partir relógio; seu planejamento de vida é ser assaltante de banco, ser um bicho solto, "estrupador", dar trabalho à polícia.

Verifica-se aqui, de modo claro, uma reação quase que de revanche, uma resposta que parece pretender chocar seu interlocutor com as significações que aí afloram. O que chama atenção aqui, porém, mais do que isso, é que essas discursividades em torno aos temas abrigam uma forte profanação da fala de autoridade que geralmente acolhe os temas discutidos: vida em sociedade, religião, polícia, governo. Daí advém esse sentido de afronta, de rebeldia, de desrespeito que se verifica nessas palavras, para aqueles que assimilaram a palavra de autoridade: como entender de outro modo o sujeito dizer que sua igreja é "fumar maconha, partir relógio"? Que seu plano de vida é ser estuprador?

A palavra de autoridade, devido mesmo a seu caráter de imposição, que você incorpora se você a reconhece como tal, não é aqui assimilada pelo interlocutor/o garoto de rua. Antes ainda, aqui se apresenta uma relação de hostilidade do menino de rua em direção à palavra de autoridade, intuída na palavra do seu interlocutor, o qual é, no seu entender, um legítimo representante daquela palavra. 0 menino de rua deixa marcada essa relação de hostilidade em direção a essa palavra e o seu não reconhecimento, chegando mesmo ao gesto da profanação.

Não se trata, nessa perspectiva, de dizer que as significações oficiais, cristalizadas em torno aos diversos temas tratados nessas entrevistas aqui arroladas, são significações não acessíveis por esses sujeitos. Ou que esses sujeitos, por estarem, de um lado, acolhidos em uma instituição de assistência; ou, de outro, por viverem livremente transitando nas ruas da cidade, sem que lhes seja cobrado ou exigido coisa alguma, vão agir de 
acordo com essas circunstâncias - demonstrando uma competência comunicativa de saber o que fala, a quem fala, em que situação -, quer seja, aderindo, por precaução, aos saberes reconhecidos naquele espaço institucional em que eles circulam; quer seja agindo livremente, por não se sentirem ameaçados, e respondendo conforme seus desejos de afrontar e chocar as pessoas com quem interagem naquele momento. Mais do que isso, ainda que essa competência possa estar, em graus variados, sustentando essas posturas e comportamentos lingüísticos, as diferentes respostas dos entrevistados (todos eles meninos de rua) podem iluminar a discussão sobre a questão da natureza da palavra dialógica e da heteroglossia constitutiva da nossa fala e dos meios de transmissão e assimilação da palavra de outrem em nossos discursos.

No caso, a entrada em cena de temas vinculados às significações em torno a instituições básicas e a normas e praxes de convivência em sociedade, solidamente cimentadas por discursividades impostas e sacramentadas por dizeres marcados ideologicamente e difundidos por importantes meios de funcionamento das sociedades, como a Escola, a Família, o Governo, etc., faz aparecerem as diversas formas de relação com a palavra de autoridade, essas palavras que existem antes de nós, que nos recebem quando nascemos, as quais não necessariamente assimilamos nem de que nos servimos. São palavras que não admitem discussão.

A palavra de autoridade intuída na resposta ou na responsividade ativa de que é portador o seu interlocutor não é assimilada por esses meninos, não é reconhecida por ele nem por seu grupo. Se reconhecida, a palavra de autoridade comporia com o restante da fala, o nosso discurso, na qualidade de um bloco monolítico acrescentado ao que já temos, sem sofrer alteração: essa é a palavra de autoridade. A palavra de autoridade não admite negociação de sentido: ela deve compor, tal como é, em sua integridade, a fala do sujeito. Ou então ela não faz a composição.

No caso, é inegável que há uma rejeição, há um total desconhecimento dessa palavra, uma hostilidade em relação a ela, traduzida em profanação, em adulteração do sentido dessa palavra de autoridade.

A passagem abaixo é trecho transcrito também de uma conversa com meninos de rua e as mesmas pessoas que fizeram a entrevista anterior. Nesse trecho, vê-se uma outra forma de desenvolvimento da conversa, sem o tom de desafio imposto àquela, mas, do mesmo modo, aí se observa a recusa à palavra de autoridade: essa palavra não faz o menor sentido para esse menino entrevistado. As significações preconizadas pelos temas propostos para discussão, tal como admitido como palavra de autoridade, pré-existente, não encontram qualquer eco nas falas dessas pessoas: 
ENT_Eu queria saber o que é que você acha do país que você vive. _ É, tá muita miséria, muita pobreza, é muita gente se lenhando pelos cantos aí afora...

_ Sim, você acha que a pobreza é razão ou motivo prá levar as pessoas assaltar as outras pessoas também?

_ É, tem a ver.

Por que assim? Você acha que talvez as pessoas sejam obrigadas a assaltar outros assim?

É... a gente às vez fica sem dinheiro e o único jeito que a gente tem é roubar.

_Então o único jeito é roubar mesmo. É, como é que você acha que o menor de rua brasileiro está sendo tratado hoje em dia, hein?

_É, véio, ninguém liga prá nada.

Nos segmentos em negrito, o garoto fala com naturalidade da possibilidade do roubo assentada na absoluta falta de condição do indivíduo na sociedade: a falta de dinheiro que garantiria o alimento e tudo mais torna natural a emergência do roubo. A idéia de que o roubo não se justifica, em hipótese alguma é cogitada e a palavra de autoridade é profanada: o roubo é perfeitamente justificado. Nesse caso, não parece haver o tom de uma afronta ao seu entrevistador, tal como se verificou na gravação anterior, talvez em função da ironia que parece percorrer o fragmento transcrito anterior. Mas a palavra de autoridade é igualmente profanada, adulterada em sua essência.

Assim, o entendimento desses valores colocados - no caso, a ilegitimidade do roubo sob qualquer situação, ainda que na visível precariedade do indivíduo/sujeito para sobreviver - não se sustenta aqui, nesse fragmento de conversa entre um menino que vive nas ruas da cidade, acompanhado de seus pares, amigos, familiares, companheiros de feitos, e um estudante universitário da mesma comunidade, componente de um outro grupo social, cujos valores são assentados na palavra de autoridade que circula na sociedade como um todo, como meio de impedir os excessos das pessoas no trato social com seus pares, excesso que se traduz, por exemplo, no feito que aqui se verifica: o roubo.

O estudo dos meios de transmissão do discurso de outrem em nosso discurso, a consideração das palavras configuradas por Bakhtin como a palavra internamente persuasiva, a palavra contemporânea, e a palavra de autoridade, aquela que vem de fora, que nos é imposta, possibilitam interpretações mais condizentes com o real movimento da língua e de seu funcionamento nas sociedades: a compreensão da língua abstratamente caracterizada, sem atinar para o jogo de linguagem que se observa no funcionamento das sociedades através da comunicação entre as pessoas, inviabiliza o entendimento com clareza das relações entre os homens e dessas diferenças no tratamento do objeto de que se discute na conversação e da 
consideração do dialogismo em direção ao interlocutor e sua responsividade ativa: o modo como ele compreende e reage ao que foi proposto por seu parceiro de fala.

\section{CONCLUSÃO}

A palavra de autoridade e a palavra internamente persuasiva são duas categorias da palavra de outrem que se transmitem nas interações dialógicas de que participamos no decorrer de nossas vidas. E essas palavras têm um invulgar poder na formação de nossas consciências ideológicas, o que se traduz pelo modo como se dará, para nós, o entendimento do que ocorre à nossa volta, quais as nossas respostas e quais as nossas perguntas diante do que vivemos; quais as nossas reações ao que vivemos.

A responsividade do interlocutor não deve ser entendida como uma simples alternância de enunciados, mas como enunciados/respostas marcados por índices sociais de valor, estabelecidos e organizados em estratificações axiológicas, constituindo as vozes sociais. O funcionamento das sociedades se faz em meio a essa diversificação. Em Faraco (2001, p. 2) lê-se, com clareza de compreensão, uma expressão do funcionamento das sociedades humanas e de como a língua e a cultura aí se entrelaçam na formação do homem sujeito social:

É no interior desse caldo de múltiplas vozes em múltiplas relações
que nascem e se constituem os seres humanos. Para cada um, a
realidade cultural se apresenta como um mundo de vozes e suas
relações de aceitação e recusa, suas convergências e divergências,
suas harmonias e seus conflitos, suas intersecções e hibridizações ${ }^{6}$.

O silêncio, tão forte nos trechos transcritos, registros de fala, de língua viva, colhida em situação real de comunicação, pode ser visto e entendido não tão naturalmente como alguns consideram, à moda de um recurso de que se serve o falante/ouvinte/interlocutor, perfeitamente cônscio de que a significação que está em jogo em torno ao objeto - os temas de família, escola, honestidade, sociedade e outros - é uma significação única da qual ele não partilha, nada tendo a dizer, em conseqüência. E, num assomo de cuidados em função dessa situação de assimetria que aí se estabelece, em que o seu interlocutor é considerado de maior poder e maior prestígio, o falante resolve silenciar.

Fragmento traduzido pelo próprio autor, em texto xerocopiado. 
Em outras situações de fala, gravadas agora com pessoas que ocupam posições mais humildes na sociedade, por exemplo, pessoas que realizam trabalhos domésticos e outras funções menos prestigiadas na sociedade, também se encontram esses silêncios, essas evasões, essas recusas em resposta a perguntas sobre temáticas semelhantes a essas aqui discutidas. Não há aí o ingrediente do temor em face de uma situação de perigo, como a que pode caracterizar o diálogo entre meninos de rua e pesquisadores de maior prestígio socioeconômico e cultural, por exemplo. Mesmo assim, o silêncio aparece. Nesses casos também se pode aventar sobre a razão desse silêncio como uma reação à palavra de autoridade ainda não plenamente reconhecida pelo falante, e, na seqüência, não assimilada.

Dentro da perspectiva bakhtiniana de dialogia da palavra e da heteroglossia de nosso discurso, o estudo das categorias de palavras de autoridade e palavras internamente persuasivas e das relações entre elas nos procedimentos de transmissão do discurso de outrem não somente em situações de fala assimetricamente constituídas - como as que aqui trabalhamos - mas também naqueles diálogos não assimetricamente constituídos, permite analisar os enfrentamentos entre a palavra de autoridade e aquelas internamente persuasivas na história da formação ideológica do indivíduo; e fornece bons critérios para compreendermos melhor como a língua(gem) funciona nos diálogos cotidianos, a base da vida da linguagem, e qual sua função no desenvolvimento cultural-ideológico do ser humano.

\section{RESUMO}

Em conversas gravadas com meninos e meninas de rua, na cidade de Salvador, observou-se a presença constante do "silêncio" e da recusa em responder questões colocadas por seus entrevistadores - professores e estudantes universitários. Neste texto, procura-se compreender melhor a emergência desses silêncios e recusas diante das questões colocadas, na maioria delas questões referentes a funcionamento das instituições sociais como família, escola, polícia. A leitura de Bakhtin em torno à língua(gem), os conceitos de heteroglossia e da natureza dialógica da língua(gem), de vozes sociais e de palavras de autoridade e palavras internamente persuasivas como palavras que constituem a nossa fala, mostraram caminhos bastante esclarecedores na explicação desses comportamentos lingüísticos, principalmente em situações de fala descritas como assimetricamente 
constituídas, mas não apenas nelas.

Palavras-chave: dialogismo; heteroglossia; palavra de autoridade; palavra internamente persuasiva.

\begin{abstract}
This article investigates the reason why boys and girls living in the streets of Salvador use silence and refusal to answer questions posed by interviewers (university professors and students), mostly when questions refer to social institutions such as family, school and police. The results of this research shed light on better understanding the linguistic behavior of people, mainly when they find themselves in asymmetrically constituted speech, but not only in such situations, through Bakthin's concepts of language, heteroglossia, the dialogic nature of language, social voices and authoritative discourse and internally persuasive discourse as constituents of our speech.

Key-words: dialogism; heteroglossia; authoritative discourse; internally persuasive discourse.
\end{abstract}

\title{
REFERÊNCIAS
}

BAKHTIN, M. M. O Discurso no Romance. In: Questóes de Literatura e Estética. A teoria do romance. São Paulo: Anna Blume/Hucitec, 1988.

FARACO, Carlos Alberto. Some sources of Bakhtin's dialogism seen in great time. In: ZYLKO, Boguslaw (Ed.). Bakhtin \& his intellectual ambience. Gdansk: Wydawnictwo Uniwersytetu Gdanskiego, 2002. p. 49-58.

MARKOVA, Ivana; FOPPA, Klaus (Eds.). Asymmetries in Dialogue. U.S.A.: Harvester Wheatsheaf Barnes \& Noble Books, 1991.

LINELL \& LUCKMANN. Asymmetries in dialogue: some conceptual preliminaries. In: MARKOVA, Ivana; FOPPA, Klaus (Eds.). Asymmetries in Dialogue. U.S.A: Harvester Wheatsheaf Barnes \& Noble Books, 1991. p. 3. 